\section{Perspectivas para os estudos sobre Internet, Política, Democracia e Estado Digital \\ [Perspectives for studies on the Internet, Politics, Democracy and Digital State]}

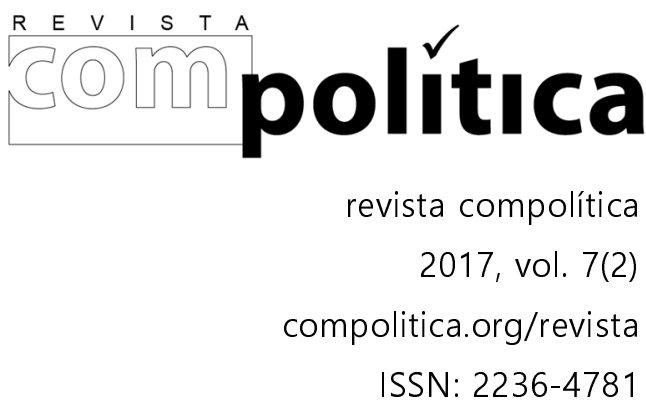

DOI: 10.21878/compolitica.2017.7.2.345 () Open Access Journal

\begin{abstract}
Resenha do livro Democracia Digital, Comunicação Política e Redes - Teoria e Prática, organizado por Sivaldo Pereira da Silva, Rachel Callai Bragatto e Rafael Cardoso Sampaio.
\end{abstract}

\author{
Ana Beatriz Brêtas \\ Universidade Federal Fluminense \\ [Fluminense Federal University]
}

\author{
Viktor Chagas \\ Universidade Federal Fluminense \\ [Fluminense Federal University]
}

\begin{abstract}
Resumo
Organizado por Sivaldo Pereira da Silva, Rachel Callai Bragatto e Rafael Cardoso Sampaio, o livro Democracia Digital, Comunicação Política e Redes - Teoria e Prática reúne artigos de alguns dos principais pesquisadores brasileiros debruçados sobre as temáticas de Internet, Política, Democracia e Estado Digital. Esta resenha apresenta brevemente os catorze artigos que compõem a obra. O exemplar é rico em estudos de caso e proporciona uma perspectiva transdisciplinar das discussões. A leitura é indicada para todos aqueles que desejam se situar no campo de estudos, trazendo as questões e desafios mais relevantes para a agenda atual de pesquisas na área.
\end{abstract}

Palavras-chave: Democracia Digital, Internet, Política, Estado Digital.

\begin{abstract}
The book Digital Democracy, Political Communication and Networks - Theory and Practice, organized by Sivaldo Pereira da Silva, Rachel Callai Bragatto and Rafael Cardoso Sampaio, brings together articles by some of the leading Brazilian researchers on Internet, Politics, Democracy and Digital State issues. This review briefly presents the fourteen articles that make up the work. The sample is full of case studies and provides a transdisciplinary perspective of the discussions. The reading is indicated for all those who wish to be in the field of studies, bringing the most relevant issues and challenges to the current research agenda in the area.
\end{abstract}

Keywords: Digital Democracy, Internet, Politics, Digital State. 


\title{
Perspectivas para os estudos sobre Internet, Política, Democracia e Estado Digital
}

\author{
Ana Beatriz BRÊTAS \\ Viktor CHAGAS
}

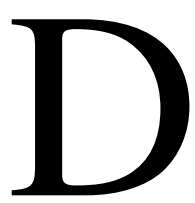
esde sua popularização, em meados dos anos 1990, a internet e seus efeitos sobre a sociedade chamam a atenção dos pesquisadores das ciências humanas. Se o surgimento da internet social despertou inicialmente previsões otimistas sobre a expansão da participação civil e pluralização dos discursos políticos, mais de 20 anos depois os estudos sobre a temática se expandem e congregam múltiplas perspectivas.

É na exploração dessa diversidade que aponta o exercício de composição de Democracia Digital, Comunicação Política e Redes - Teoria e Prática, organizado por Sivaldo Pereira da Silva, Rachel Callai Bragatto e Rafael Cardoso Sampaio e com a contribuição de 22 autores, de mais de 13 instituições diferentes. O volume reúne 14 artigos de pesquisadores e especialistas de áreas como a comunicação, ciência política, economia, estatística, administração, ciências sociais, entre outras. Juntos, abrangem discussões teóricas e empíricas que congregam as principais questões relacionadas à política, democracia e tecnologias da informação em uma perspectiva interdisciplinar.

O livro está estruturado em duas partes. A primeira intitula-se Teoria, perspectivas $e$ desafios e a segunda Experiências e Práticas. A Parte I se desdobra nas seções Estado da Arte e Horizontes, na qual o leitor é contextualizado na formação e nos rumos do campo de conhecimento sobre a Democracia Digital e suas áreas afins; e Desafios e Tendências, em que quatro capítulos elencam alguns dos obstáculos conceituais e práticos que se elevam à frente dos objetivos de implementação desses projetos. A Parte II é composta pelos blocos Consultas e Participação, que lança olhares sobre alguns dos projetos brasileiros de participação online, pontuando seus limites e potências; e Abertura e Direito à Informação, em que são acirrados os debates sobre transparência e accountability. 
Esta resenha, por sua vez, divide-se em três seções: Construção dos campos de conhecimento, Desafios e Estudos de caso. As duas primeiras seguem as divisões propostas pelos organizadores do livro. Entretanto, optamos por analisar em conjunto os textos sobre experiências e práticas, considerando que, apesar do enfoque em temas diferentes, há uma frente de diálogo sob a qual se pode encará-los.

\section{Construção dos campos de conhecimento}

O primeiro momento do livro objetiva mapear os fundamentos sob os quais os campos exploratórios são desenvolvidos. No artigo Concepções, debates e desafios da democracia digital, Sivaldo Pereira, Rafael Cardoso Sampaio e Rachel Callai Bragatto caminham no sentido de dar ordem à heterogeneidade teórica que permeia as produções da área, bem como apontar os desafios decorrentes da expansão das investigações sobre a matéria.

Como definição basilar, entende-se a democracia digital como referente "ao uso das tecnologias digitais para concretizar avanços no ideário democrático" (Pereira, Sampaio e Bragatto, 2016, p.19). O capítulo se dedica a destrinchar, inicialmente, duas vertentes de abordagem sobre o tema: a social e a institucional. A primeira pensa o ciberespaço como local de fortalecimento de laços entre grupos de interesses e de aprimoramento do debate político. A segunda está preocupada com o uso da internet para a aproximação entre o sistema político e o cidadão e a adequação das instituições às tecnologias digitais. Em seguida, o texto enuncia algumas das compreensões teóricas sobre a democracia que ancoram as pesquisas.

Os autores finalizam a reflexão relacionando alguns dos desafios que atravessam o campo, categorizando-os em (a) sociais; (b) institucionais; (c) tecnológicos; e (d) epistemológicos. Os primeiros desafios englobam aspectos relativos à garantia de uma representatividade eficiente da esfera civil nas iniciativas de participação online. O segundo grupo refere-se às dinâmicas institucionais que podem representar entraves à implementação de projetos na área. A via tecnológica diz respeito às implicações que as especificidades dos diferentes meios têm no sucesso ou não das políticas de democracia digital. Questões 
epistemológicas, enfim, abarcam principalmente aquilo que concerne à demanda crescente por utilização de dados nas pesquisas e seus desdobramentos na rotina do pesquisador.

Continuando os esforços de uma análise extensiva da produção acadêmica, Wilson Gomes apresenta o artigo 20 Anos de Política, Estado e Democracia Digitais, no qual ocupa-se em compreender a formação e evolução deste campo de conhecimento. Para isso, realiza a coleta de 4.252 artigos, em sua maioria de língua inglesa, que dão conta da circulação internacional da matéria. Além de traçar um histórico do desenvolvimento do campo, o autor se empenha em elucidar os múltiplos conceitos que o formaram. Os estudos sobre democracia digital são localizados junto a outras duas subáreas de investigação: a da Política On-line e a do Estado Digital.

A subárea da Política On-line é aquela que procura compreender os impactos das comunicações digitais sobre objetos tradicionais das pesquisas políticas, como Movimentos Sociais, Ação Política, entre outros. Estado Digital compõe um campo de investigação interessado no uso das novas tecnologias por instituições políticas para promover a participação civil, auxiliar a entrega de serviços, etc. Nesta divisão, são entendidos como trabalhos sobre Democracia Digital aqueles que "adotam ou discutem abordagens normativas do universo das comunicações digitais baseadas em alguma noção de democracia" (Gomes, 2016, p.65). Os subtemas centrais elencados pelo autor são: Teorias da democracia liberal; Deliberação; Participação; Digital Divide e Transparência.

A partir dessa distinção, Gomes demonstra a progressão das subáreas ao longo dos anos, as interseções entre elas, assim como os índices de popularização de suas temáticas. A organização proposta pelo artigo é interessante para situar o leitor-pesquisador dentro do universo de produções que envolvem tecnologias da informação e política.

No capítulo A Construção do Campo de Internet e Política - Análise dos Artigos Brasileiros Apresentados entre 2000 e 2014, Rafael Cardoso Sampaio, Rachel Callai Bragatto e Maria Alejandra Nicolás voltam sua observação para as pesquisas de pesquisadores brasileiros das ciências sociais sobre o tema "Internet e política". Os autores examinam evolução da área de investigação ao longo dos anos e tentam compreender se esta pode ser reconhecida como um campo de conhecimento. Para isso, empreendem uma 
análise de 526 artigos, apresentados entre 2000 e 2014, em 11 eventos de diferentes especialidades.

Os resultados são extensos e expõem variadas características dos artigos. São averiguadas as instituições dos autores e suas localizações, assim como a área de formação; a vertente, se os artigos enfatizam aspectos institucionais ou sociais do debate; a principal linha teórica; qual plataforma tecnológica e qual objeto político é investigado, em eventuais estudos de caso; e as variáveis metodológicas, se a abordagem é teórica ou empírica, que métodos são utilizados, etc.

Os autores concluem que tem havido uma expansão em relação a esses estudos, porém, "Internet e política" ainda aparece neles mais como temática interdisciplinar do que enquanto propriamente um campo de estudos. Traçando um paralelo entre este artigo e o anterior, que propunha o exame da consolidação internacional do campo, pode-se observar algumas peculiaridades do cenário brasileiro. Ambos os levantamentos se deparam com um aumento das produções sobre a temática nos anos de 2009-2010, mas o segundo faz uma associação entre este crescimento e o começo do uso das mídias digitais em campanhas eleitorais, uma vez que boa parte das produções nacionais da Comunicação e Política estão voltadas para o cenário eleitoral.

Por fim, o capítulo aponta para o baixo índice de produções interdisciplinares, assim como de circulação de autores em eventos fora de sua área de origem. Faltam também eventos dedicados exclusivamente a temática, o que já é abundante no cenário internacional. Em uma via positiva, percebe-se o surgimento de instâncias de pesquisas interdisciplinares dedicadas ao tema.

A primeira seção do livro apresenta as múltiplas possibilidades de desenvolvimento de pesquisas na área, facilitando aos investigadores pensarem os recortes de seus trabalhos. Há também um importante esforço dos autores em elucidar os conceitos que alicerçam as discussões apresentadas e colocá-las em diálogo com diferentes subáreas que as compõem. 


\section{Desafios para o campo}

No artigo que inicia o segundo bloco de reflexões, Mecanismos de Dominação Simbólicas nas Redes de Participação - Política Digital, Christiana Soares de Freitas suscita a provocação acerca dos limites dos projetos de participação política on-line no que tange à inclusão. A autora expõe uma série de análises sobre essas iniciativas, que indicam preponderância de indivíduos com rendas e graus de escolaridades mais altos e levanta o debate sobre a reprodução de desigualdades nos espaços de e-participação.

Com base em Bordieu, o campo político é pensado como um "microcosmo que obedece às próprias leis" (Bordieu apud Freitas, 2016, p.128) e que guarda, por isso, seus próprios critérios de valorização e credibilidade. A autora considera que é preciso absorver o habitus desse microcosmo para tomar parte em seus debates. A acumulação de capital político é pré-condição vital para que os cidadãos sejam reconhecidos e se reconheçam nos espaços de poder. Os temas de dominação simbólica e exclusão digital se entrelaçam e o artigo aponta para as iniciativas vindas da sociedade civil como aquelas com maior potencial de ruptura e empoderamento popular.

Em Tendências Democráticas e Autoritárias, Arquiteturas Distribuídas e Centralizadas, Henrique Z.M. Parra e Alexandre Hannud Abdo trazem os olhares para uma dimensão tecnopolítica do debate sobre a internet, a partir da identificação da dicotomia entre os ganhos democráticos da internet e suas potências autoritárias. Os autores pincelam novas formas de exercício de poder que emergiriam com a chegada desses meios específicos, destacando como bases teóricas as produções de Lewis Mumford (1964) e Langdon Winner (1986).

Parra e Abdo defendem o anonimato on-line como condição essencial para evitar desvios autoritários no uso destas tecnologias e chamam a atenção para os protocolos e gerenciamento de dados como etapa de controle social. Os autores finalizam o artigo apontando algumas das forças virtuais centralizadoras para as quais é preciso se atentar: as relações entre megacorporações de telecomunicações e governos dos países onde elas operam; os efeitos de rede e interoperabilidade dependente - que acontecem quando a 
popularização de um serviço on-line torna seu uso inevitável, quando serviços são disponibilizados gratuitamente em troca de consumo de publicidade, entre outros.

No artigo Medição do Uso da Internet para a Participação, Manuella Maia Ribeiro e Alexandre Fernandes Barbosa identificam uma lacuna nos estudos voltados à medição da efetividade dos projetos de democracia digital no Brasil. O capítulo propõe uma análise dos indicadores medidos pelo Centro Regional de Estudos para o Desenvolvimento da Sociedade da Informação (Cetic.br) ${ }^{1}$ sobre governo eletrônico.

Os dados demonstram que, em 2015, apenas 51\% dos lares brasileiros tinham acesso à internet e somente $4 \%$ dos usuários participaram com sugestões e opiniões de fóruns, chats, websites e outras iniciativas do governo. Com base nos indicadores, a pesquisa aponta três desafios centrais para ampliação da participação civil nos órgãos públicos. São eles: i) a diminuição da exclusão digital; ii) a ampliação do relacionamento dos usuários da internet com as organizações públicas; iii) maior disponibilidade de iniciativas de participação online. De acordo com os autores, a participação on-line é uma das áreas menos desenvolvidas do uso das tecnologias digitais em órgãos públicos.

A análise de Ricardo Fabrino Mendonça e Marcus Abílio Pereira publicada no artigo Dilemas na Apropriação das TICs pela ALMG: uma Análise sobre a Percepção dos Gestores propõe uma perspectiva metodológica baseada em entrevistas com servidores da Assembleia Legislativa de Minas Gerais. O interesse é compreender quais são, na visão destas pessoas, os entraves para o efetivo funcionamento de projetos que promovam a aproximação entre governo e sociedade através das tecnologias de comunicação.

Um dos argumentos centrais do artigo é o de que a indisposição dos representantes não é o principal empecilho na realização desta demanda. Nas entrevistas, os membros da Assembleia listaram até cinco outros óbices, que vão desde adversidades na organização administrativa do parlamento à exclusão digital. O capítulo propõe também uma retomada histórica do projeto de aproximação entre representantes e representados na ALMG e esclarece que a implementação do uso das tecnologias de informação para esse fim é apenas

\footnotetext{
${ }^{1}$ O Cetic.br produz regularmente estatísticas sobre o uso das TICs no Brasil para o estreitamento dos laços entre governo e sociedade.
} 
uma dentre uma sequência de iniciativas, que começam a acontecer na instituição ao final dos $\operatorname{anos} 70$.

Na segunda seção de capítulos, o tema da exclusão digital é citado em três dos quatro artigos que a compõem, o que o coloca como agenda significativa. Os dois capítulos finais também apontam para as questões envolvendo o uso autoritário das tecnologias da informação e para os empecilhos que a estrutura interna das instituições públicas pode trazer à implementação de iniciativas de participação. A análise de Fabrino e Pereira, especialmente, por apresentar diversos obstáculos, demonstra a complexidade desta problemática e a variedade de vias analíticas que podem ser levadas em conta para os que desejam solucioná-la.

\section{Estudos de caso}

A segunda parte do livro congrega um conjunto de discussões que se estruturam sobre estudos de caso. Enquanto o bloco final incorpora artigos que consideram as questões da abertura de dados e accountability, o primeiro abordará as experiências de deliberação online e de participação cidadã na tomada de decisão.

Letícia Capone, Arthur Ituassu, Sérgio Lifschitz e Vivian Mannheimer abrem esta seção com o artigo Superposters, Especialização e Serviço: a Primeira Consulta Pública do Marco Civil da Internet no Twitter. Os autores executam um rastreamento da hashtag \#marcocivil no Twitter, a fim de levantar dados sobre o engajamento civil na consulta pública para a elaboração da lei referente ao Marco Civil da Internet ${ }^{2}$. Ela foi realizada em um fórum hospedado no site Cultura Digital e no site Twitter, através da hashtag que é objeto desta pesquisa.

A investigação dedicou-se a depreender: (1) quem eram os participantes da conversa no espaço-tempo observado; para isso, analisou-se o índice de postagens por usuário e o seu perfil, a fim de depreender o posicionamento social e o grau de especialização no debate;

\footnotetext{
${ }^{2}$ Lei $n^{\mathrm{o}} 12.965$, de 23 de abril de 2014.
} 
(2) que tipo de mídia esteve presente; de quais veículos eram os links compartilhados nos tweets e se eram ou não especializados e (3) quais foram os principais temas abordados.

As conclusões indicam um alto índice de concentração de postagens por usuário, assim como de participação de usuários especializados. As mídias compartilhadas também eram, em sua maioria, especializadas. Os autores apontam, como ganho, que as postagens mobilizaram discussões diretamente relacionadas ao Marco Civil da Internet, como privacidade, anonimato e neutralidade na rede.

Tal qual o capítulo anterior, o artigo O Uso de Fóruns On-Line na Eleição do Conselho Nacional de Políticas Culturais: Modos de Apropriação por Eleitores, Candidatos e Governo, de Sivaldo Pereira da Silva, examina uma iniciativa de participação promovida pelo Ministério da Cultura. No caso, a etapa estadual da eleição de delegados para o Conselho Nacional de Políticas Culturais, realizada através de uma plataforma virtual.

Além da possibilidade de eleição de representantes via internet, o projeto contava com um fórum para discussão pública. $\mathrm{O}$ artigo é focado em uma análise das dinâmicas interacionais entre os participantes que compõem a rede: votantes, candidatos e membros do governo. O autor levanta um conjunto extenso de dados sobre o processo, como o volume de postagens por estado e por setor do fórum, o índice de participação dos diferentes tipos de agentes e a tipificação dos conteúdos das mensagens.

Entre outras conclusões, notou-se a alta incidência de postagens em fóruns com temáticas mais tradicionalistas (literatura, livros e leitura; culturas populares e culturas afrobrasileiras) se comparados com aqueles atravessados por assuntos mais técnicos e tecnológicos (artes visuais; arquitetura e urbanismo; arte digital e moda). O artigo também indica que a maior parte dos inscritos na plataforma não participou das discussões e que os debates nesse ambiente contavam com um baixo índice de trocas argumentativas, sendo o diálogo geralmente cordial, com agradecimentos ou congratulações.

Débora C. Rezende de Almeida assina o artigo Instituições Participativas, Accountability e Mídias Sociais: o Conselho Nacional de Assistência Social. Nele, tenciona-se pensar as mídias digitais como canais de promoção de accountability, através da observação do website, blog e fanpage do Conselho Nacional de Assistência Social. 
A investigação é feita com base em categorização dos conteúdos e comparação das publicações nas diferentes mídias. O artigo testa e comprova a hipótese de que canais que possibilitam um maior grau de interatividade e guardariam o potencial de aproximação entre sociedade e governo vêm sendo usados em formato Web 1.0. A indagação é embasada por uma farta discussão teórica sobre accountability, na qual a autora defende uma fundamentação que transpasse a dimensão de transparência e acesso à informação e agregue também a justificação pública como critério.

No artigo A Comunicação das Prefs: Considerações Preliminares Sobre o Alcance do Facebook como Ferramenta de Democracia Digital, Lenise Klenk e Kelly Prudêncio organizam um estudo sobre três fanpages de prefeituras municipais no Facebook, com ênfase no case de Curitiba. A auto-apelidada Prefs chamou atenção na internet por promover em seu perfil uma interação descontraída com o público, que rendeu altos índices de engajamento e se tornou modelo para outras instituições. As pesquisadoras se questionam em que medida este sucesso contribui na relação entre representantes e representados.

A metodologia se foca no exame das publicações de mais alcance e verifica se traduzem práticas de aperfeiçoamento da democracia. A análise observou se nas postagens estão incutidos valores de (a) Governo Eletrônico: divulgação de serviços ou projetos da Prefeitura; (b) E-participação: espaço para debate público sobre temas socialmente relevantes; (c) Accountability e transparência: acesso a dados públicos, informações que permitam ao cidadão físcalizar as medidas do poder público; (d) Informal/relacionamento: conteúdo de humor e entretenimento, mensagens institucionais em datas comemorativas.

Além da fanpage de Curitiba, entram na matéria exemplos de Manaus, Maceió e São Paulo. Os resultados concluem que a interação na página não se converte em um estreitamento de laços entre cidadãos e elite política. Todavia, nota-se que a linguagem lúdica tem sido usada para chamar a atenção para discussões cívicas relevantes e informar a população sobre serviços e projetos das prefeituras.

Ao encontro deste debate vai a análise de Ana Claúdia Farranha e Viviane Silva dos Santos, em Governo Eletrônico, Democracia Online e Direito à Informação: Análise do Perfil em 
Redes Sociais da Secretaria de Políticas de Promoção de Igualdade Racial (Seppir/Brasil). O capítulo se dedica a compreender as dinâmicas de interação entre os perfis da Seppir no Facebook e no Twitter e seus seguidores. Deseja-se averiguar se a presença neste ambiente facilita à secretaria propor, monitorar e avaliar projetos, programas e políticas públicas sobre ações afirmativas.

Em termos teóricos, a investigação se apoia em uma "visão forte" de governança eletrônica, ancorada não só na disponibilização de serviços online como também no esforço de ampliação da participação democrática. As autoras apostam em uma metodologia mista que combina análise de conteúdo, de curtidas da página e entrevistas aprofundadas. A pesquisa ressalta a importância da multiplicação de mídias on-line que publicizem a discussão sobre a temática racial, favorecendo a formação de opinião crítica junto aos usuários da rede.

Entretanto, aponta também os avanços necessários a um melhor desempenho da Seppir nas redes. Os espaços digitais são usados prioritariamente para fins informativos, com baixos índices de interatividade e responsividade. Embora reconheçam que estas publicações tenham sua importância, as autoras atentam para a necessidade de tornar a sociedade inteirada não apenas do que é feito na secretaria, mas também da contribuição destas ações para a formulação de políticas públicas.

Ana Júlia Possamai tece no artigo Portal Brasileiro de Dados Abertos: Novas Práticas para o Fortalecimento da Democracia e da Gestão Pública na Era Digital uma discussão sobre open government data. A autora remonta às origens do "Governo aberto" e apresenta suas propostas, formatos e aplicações no Brasil. Iniciativas do governo federal como o Portal Brasileiro de Dados Abertos, a Política de Infraestrutura Nacional de Dados Abertos e a Política de Dados Abertos no Poder Executivo Federal são analisadas a partir dos principais avanços e desafios nacionais.

No Brasil, dados públicos já vêm sendo disponibilizados por órgãos governamentais há anos, entretanto a partir de experiências descentralizadas. Mais recentemente, ações como a criação do Portal Brasileiro de Dados Abertos procuram dar conta desta unificação, mas ainda com falhas como a classificação não-adequada de determinados dados, a ausência de 
licenças para uso, etc. Neste sentido, o capítulo finaliza suas reflexões com uma análise da Infraestrutura Nacional de Dados Abertos, responsável por definir, estruturar e coordenar a política de dados abertos no governo federal brasileiro.

O livro é finalizado com o artigo Netizen em Ação: Hackeando o Parlamento a Partir de Dentro, de Cristiano Ferri Faria, Malena Rehbein Rodrigues e André Rehbein Sathler. Os autores elaboram seus argumentos sobre o conceito de Netizen. A internet é considerada como elemento modelador de uma reconstrução do imaginário do homem sobre si mesmo que leva a redefinição, também, da esfera pública. Em termos políticos, este novo cidadão, o Netizen, é simultaneamente emissor e receptor e passaria a estabelecer uma relação diferente com as instituições, nas quais a participação tem lugar central.

O capítulo tece uma extensa discussão teórica sobre a interação entre tecnologia e reestruturação simbólica e sua relação com os processos políticos. São abordadas também múltiplas perspectivas sobre os temas da participação e representação na democracia. Ele é finalizado com um estudo de caso, que se detém sobre o portal e-Democracia e o Lab Hacker, iniciativas do Parlamento brasileiro que estimulam cooperação cidadã na elaboração de leis, discussão pública e promovem a aproximação entre programadores, desenvolvedores e governo. Os autores destacam a importância de tais iniciativas, mas ponderam sobre a necessidade de ampliar seu alcance entre a população.

A partir dos estudos de caso reunidos no livro, percebe-se o destaque que as pesquisas têm dado à gestão pública de comunicação em sites de redes sociais, tendo em vista seu potencial de aproximar cidadãos e instituições. Não à toa os artigos que se voltaram para estes objetos estavam preocupados em observar como se desenrolavam essas relações. Os resultados demonstram que há ainda muito a evoluir. Enquanto algumas iniciativas apresentam um baixo índice de interação entre os perfis dos órgãos e os cidadãos, aquelas que conseguem promover um engajamento não chegam a propiciar uma aproximação real entre representados e elite política.

Os outros capítulos abordam projetos de participação civil nos órgãos públicos em plataformas criadas para esta finalidade. Neste caso, as ações são mais voltadas à promoção da participação e a solução de déficits democráticos. Diante disso, cabe questionar se os 
sites de mídias sociais são os mais adequados para esses objetivos. Os resultados das pesquisas apontaram que alcançar os cidadãos é um dos desafios das ações em canais alternativos. Identificamos como lacuna a baixa incidência de pesquisas que observem como as instituições coordenam o lançamento de plataformas de participação digital com a atuação em sites de redes sociais, atentando-se para os usos dados aos diferentes meios nesse processo.

\section{Considerações finais}

Democracia Digital, Comunicação Política e Redes - Teoria e Prática permeia um leque amplo de discussões sobre política e tecnologias da informação. Um de seus pontos altos é a abundância em estudos de caso, o que o torna um material auxiliar para aqueles que desejam contribuir com os avanços destas iniciativas. Por outro viés, há poucos capítulos unicamente teóricos, o que pode ser encarado como lacuna para o pesquisador interessado em tatear e construir uma definição mais precisa sobre o campo.

Os organizadores optaram por reunir investigações que partem de uma perspectiva institucional, grande parte delas tem como proposta metodológica a análise de conteúdo. Entre as conclusões dos capítulos, há diversas constatações sobre a importância de ampliar o alcance dos projetos. Entretanto, poucos trabalhos são dedicados a elucidar os entraves para esta aproximação a partir do ponto de vista dos sujeitos. Pesquisas que proponham entrevistas com os gestores públicos e os cidadãos podem suprir este hiato, trazendo contribuições importantes para os estudos em desenvolvimento.

Merecem destaque os três capítulos de abertura. Não apenas pelo extenso esforço investigativo, mas pela organização teórica que propõem. Servem como base importante para pesquisadores em formação, uma vez que expõem as múltiplas possibilidades de exploração do campo e as abordagens que se relacionam a cada uma delas. Por fim, o livro traz artigos de alguns dos principais nomes envolvidos nos estudos de "Internet e política" atualmente no Brasil, de diferentes instituições de ensino e pesquisa. É, portanto, um exemplar recomendado a todos aqueles que têm interesse em compreender o fenômeno e 
produzir pesquisas que dialoguem com seus pares e se somem aos esforços coletivos que vêm sendo empreendidos.

\section{Os autores}

Ana Beatriz Brêtas é mestranda no Programa de Pós-Graduação em Comunicação da Universidade Federal Fluminense (PPGCOM-UFF) e pesquisadora do Colab (Laboratório de Comunicação, Culturas Políticas e Economia da Colaboração). anabbretas@gmail.com

Viktor Chagas é professor e pesquisador do Programa de Pós-Graduação em Comunicação da Universidade Federal Fluminense (PPGCOM-UFF).viktor@midia.uff.br 